\title{
Adoption of IoT Technology among Elderly NCD Patients in Malaysia: A Conceptual Study Based on the Theory of Planned Behaviour
}

\author{
https://doi.org/10.3991/ijoe.v17i12.25249 \\ Chinnasamy Nambi Agamudai Malarvizhi, \\ Shamima Raihan Manzoor ${ }^{(\bowtie)}$, Sreenivasan Jayashree \\ Multimedia University, Selangor, Malaysia \\ shamimaraihanmanzoor@gmail.com
}

\begin{abstract}
Non-Communicable diseases (NCDs) are rising as the prime cause of death worldwide as well as in Malaysia. This is the result of evolutions occurring in social and economic factors in health. Some of these factors include a proliferation of business and promotion, improved style of living, change in socio-demographics, enhanced financial affordability, effortless travel and mobility, financial evolution, and import-export of unhealthy goods, causing high-risk behavioural deviations and spike metabolic hazards. Elderly people have a high chance of having NCDs because of poor sickness opposition, the impact of progressing lifestyle, terrible eating routine, and reduced amount of physical activities. At the end of the year 2020, individuals who matured by 60 years of age and above in Malaysia are anticipated to be $9.7 \%$ of the entire populace. With the arrival of numerous wearable gadgets and smart devices, the IoT (Internet of Things) gadgets are transforming the conventional medical management system into a further customised and smart one. Therefore, the objective of this study is to identify the factors that influence the actual behaviour towards IoT adoption based on the underlying concept of the "theory of planned behaviour". This study is expected to provide meaningful outcomes in creating awareness of the use of IoT among elderly NCD patients in Malaysia and understanding their behavioural intentions and actual behaviour that can help to maximise the utilisation of the available healthcare resources.
\end{abstract}

Keywords - non-communicable disease, internet of things, malaysia, elderly people, theory of planned behaviour

\section{Introduction}

Every year, non-communicable diseases (NCDs) cause over 36 million deaths which are $63 \%$ of the sum of deaths worldwide; this includes 14 million untimely deaths below 70 years. 90 out of 100 of these early demises take place in nations where the income range is middle to low, which could have been avoided. NCD comprises mainly 
cardiovascular disease (CVD), cancer and diabetes [1]. Usually, poor diet and lack of exercise, abuse of alcohol and tobacco are mutual hazardous aspects that trigger the risk of NCDs.

Irrespective of revenue, NCDs are substantial and an increasing worldwide communal health issue that is impacting every nation [2]. In the year 2011, The Malaysian National Health and Morbidity Survey which observes NCD hazards revealed that the number of obese individuals ageing 18 and above, had risen three times, since 1996; from $4.4 \%$ to a whopping $15.1 \%$ [3]. This indicates that in 2011 nearly 2.5 million Malaysian citizens matched the obesity criterion. One of the major causes for $60 \%$ of diseases in Malaysia is due to NCDs. Moreover, there is a notable rise in number to $72 \%$ in 2013 [3].

Because of enhancements in clinical sciences and advances [4], the old total populace is assessed to increment from 8.5 percent of the absolute populace in 2015 to 12 percent and 16.7 percent in 2030 and 2050, separately [5]. By 2020, man matured 60 and over in Malaysia are anticipated to be $9.7 \%$ of the total populace [6]. Consequently, added pressure has been experienced by the healthcare management system due to the rising number of the elderly NCD population and their medical needs [7]. Moreover, older people are defenceless against incessant medical issues like NCDs [8].

Although the health market is expected to reach $\$ 136.8$ billion across the world by 2021, the adoption of the internet of things (IoT) has yet been a bit slower in the healthcare sector compared to other industries to fully utilise its benefits for the well-being of people [9]. According to Abdulbaqi, Obaid and Alazawi [10], as most hospitals, clinics or other healthcare centres are trying to make preventive treatments more accessible and maintain lasting and successful treatments, it becomes imperative to analyse the adoption of IoT in this sector.

In such circumstances, the use of Internet of Things (IoT) technologies ultimately helps the development of smart systems to support and improve the processes related to biomedical and healthcare that is essential for elderly NCD patients [7]. An intelligent health support system meant for patient surveillance even in quarantines requires utilizing IoT based smart home healthcare to treat and monitor NCDs and "for decreasing needless troubles on hospitals caused by infectious diseases" [11]. Medical care can be significantly revolutionised through IoT usage. It has the capability to cut down hospital expenses through delivering good quality, cost-efficient regular care that can be done at home; easing the pressure on medical management services as well as its resources [12]. The wide-ranging term IoT encompasses gadgets and mechanisms related to sensing, some of which are radars, RFID, GPS, infrared as well as various wearable technologies.

The advent of NCDs as the principal reason for death in Malaysia as well as worldwide was the result of numerous alterations taking place in social and economic factors in health. Particularly, the effect of diabetes on society is crucial. The cost of diabetes is significant for the nation. A macro-economic study in this regard conducted in 2011 shows the cost at almost RM 2 billion. Table 1 shows selected NCD risk factors for 10 ASEAN countries including Malaysia. Japan was put together in the table to show the parametre of a developed country for comparison. Despite Malaysia's aspiration to become a developed nation by 2020 , the country's health indices for NCD risk factors are still far behind Japan. Malaysia has the highest prevalence of diabetes and obesity 
among the ASEAN countries. A comparison of multiple NCDs in both public and private primary care clinics in Malaysia is illustrated in Figure 1.

Table 1. Prevalence of selected NCD risk factors for ASEAN countries ${ }^{1}$

\begin{tabular}{|l|c|c|c|c|c|c|}
\hline & $\begin{array}{c}\text { High } \\
\text { Blood } \\
\text { Sugar } \\
\mathbf{( 2 0 1 4 )}\end{array}$ & $\begin{array}{c}\text { Raised } \\
\text { Blood } \\
\text { Pressure } \\
\mathbf{( 2 0 1 4 )}\end{array}$ & $\begin{array}{c}\text { Raised Total } \\
\text { Cholesterol } \\
\mathbf{( 2 0 0 8 )}\end{array}$ & $\begin{array}{c}\text { Obesity } \\
\mathbf{( 2 0 1 4 )}\end{array}$ & $\begin{array}{c}\text { Smoking } \\
\mathbf{( 2 0 1 1 )}\end{array}$ & $\begin{array}{c}\text { Physical } \\
\text { Inactivity } \\
\mathbf{( 2 0 1 0 )}\end{array}$ \\
\hline MALAYSIA & $\mathbf{9 . 9}$ & $\mathbf{2 2 . 1}$ & $\mathbf{1 5 . 4}$ & $\mathbf{1 3 . 3}$ & $\mathbf{2 1 . 9}$ & $\mathbf{5 2 . 3}$ \\
\hline Singapore & 8.5 & 14.1 & 17.4 & 6.2 & - & 33.1 \\
\hline Thailand & 9.7 & 21.3 & 16.7 & 8.5 & 23.5 & 14.8 \\
\hline Indonesia & 8.7 & 23.3 & 7.7 & 5.7 & 34.9 & 23.7 \\
\hline Philippines & 7.5 & 22.1 & 10.5 & 5.1 & 26.5 & 15.8 \\
\hline Viet Nam & 6.5 & 22.2 & 8.2 & 3.6 & 23.1 & 23.9 \\
\hline Myanmar & 7.1 & 23.7 & 6.4 & 2.9 & 22.0 & 9.9 \\
\hline Cambodia & 8.2 & 24.4 & 5.8 & 3.2 & 21.8 & 10.3 \\
\hline Laos & 8.6 & 24.1 & 6.7 & 3.5 & 25.7 & 10.3 \\
\hline Brunei & 11.6 & 19.3 & 16.7 & 18.1 & 18.1 & - \\
\hline Japan & 5.7 & 16.9 & 15.8 & 3.3 & 21.8 & 33.8 \\
\hline
\end{tabular}

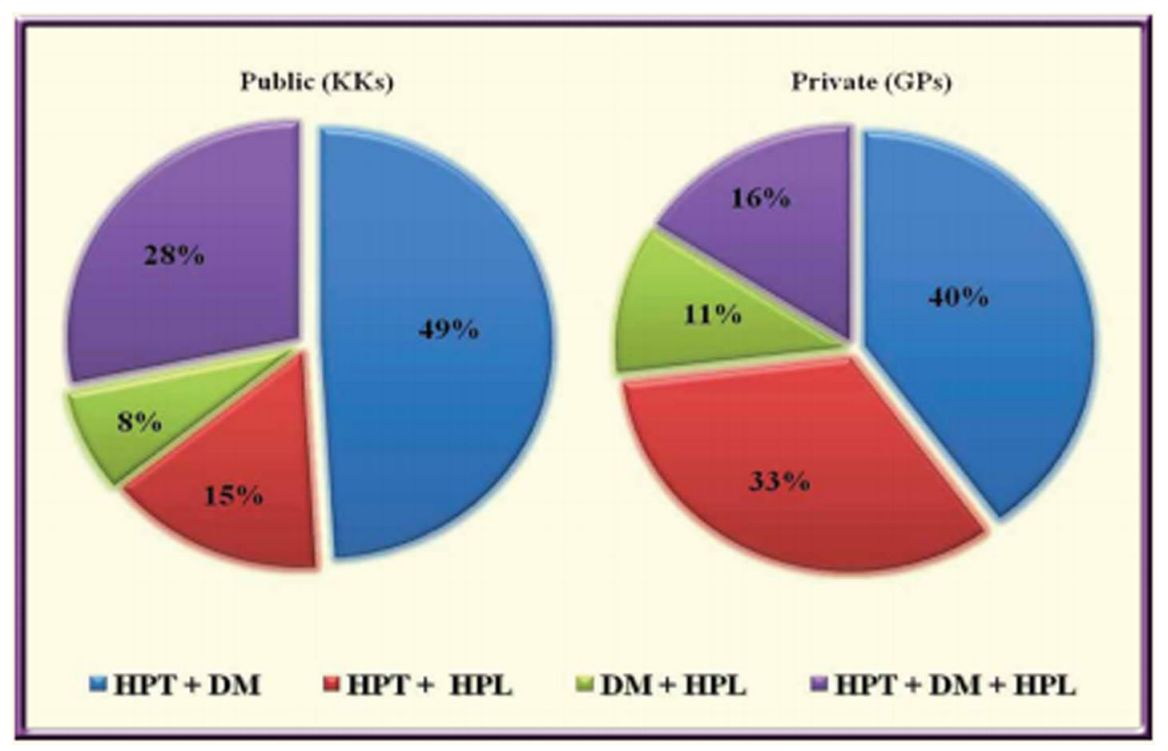

Fig. 1. Comparison of multiple NCDs in both public and private primary care clinics Note: Single disease [hypertension (HPT), diabetes mellitus (DM) or hyperlipidemia (HPL)] Source: Boyd and Fortin [13]

${ }^{1}$ Global Status Report on Non-Communicable Diseases 2014, World Health Organisation 
Some of these factors include a proliferation of business and promotion, improved style of living, change in socio-demographics, enhanced financial affordability, effortless travel and mobility, financial evolution and import-export of unhealthy goods, causing high-risk behavioural deviations and spike metabolic hazards.

Though IoT's principal target is to make our life easier and simpler, other objections may decelerate or even deter its adoption process, particularly among elderly NCD patients. Much of the earlier research in this field has emphasised the usage and design of IoT technologies from the perspective of organisations or industries [14], while only scanty focus can be found on the acceptance and awareness of IoT technologies among individual consumers such as elderly NCD patients.

Hence, the objective of this study is to identify the factors that influence the actual behaviour towards IoT adoption based on the underlying concept of the "theory of planned behaviour". The subsequent sections of this paper discuss the theoretical framework, proposed research method and conclusion along with the necessary indications for the new research directions.

\section{Literature review and theoretical framework}

\subsection{Internet of Things (IoT)}

The idea of the "Internet of Things" (IoT) comprises a collection of inspections and control applications. These rely on a system of detecting and impelling gadgets. Thus, it can act logically arranged conditions and be governed from far away through the usage of the Internet [15]. With the arrival of numerous wearable gadgets and smart devices, the IoT (Internet of Things) gadgets are transforming the conventional medical management system into a further customised and smart one. As a result, the current healthcare system is addressed otherwise as a Personalised Healthcare System (PHS).

Besides a significant cutback on costs because of improved sustainability, a notable development in patient-centric practice can be empowered if IoT technology were to be accompanied by cloud computing. In order to observe health issues, numerous researches have been conducted and 'Smart Wearable Devices (SWH)' have emerged in the past few years [16].

The medical fitness and overall welfare of aged people can be monitored by the utilisation of IoT tools and technology. Ambient assisted living, active ageing, therapy and entertainment are some of the IoT implementation instances. The core purpose of this set of applications is group observation, enhancement of lifestyle, encouragement to independent and safe living. IoT technologies have penetrated several fields of health care (Table 2). 
Table 2. Usage of IoT in health care

\begin{tabular}{|l|l|}
\hline \multicolumn{1}{|c|}{ Various Uses of IoT for Healthcare } & \multicolumn{1}{c|}{ Authors } \\
\hline Follow-up to rehabilitation therapies & $\begin{array}{l}\text { Durán-Vega, Santana-Mancilla, Buenrostro- } \\
\text { Mariscal, Contreras-Castillo, Anido-Rifón, } \\
\text { García-Ruiz, and Estrada-Gonzále [37] }\end{array}$ \\
\hline Personal monitoring of daily activities & Lun, Gordon, and Zhao [38] \\
\hline $\begin{array}{l}\text { Reminders of medical appointments and } \\
\text { medication intakes }\end{array}$ & Santana-Mancilla, and Anido-Rifón [39] \\
\hline Remote monitoring of vital signs of patients & $\begin{array}{l}\text { Bansal, Chowell, Simonsen, Vespignani, } \\
\text { and Viboud [35] }\end{array}$ \\
\hline
\end{tabular}

\subsection{Theory of Planned Behaviour (TPB)}

In the "Theory of Planned Behaviour" (TPB) context, the primary study has been on the utilisation within the marketing, promotions and PR framework [17]. Not many studies have touched on the implementation of IoT from the standpoint of multiple theories, such as the "Theory of Planned Behaviour (TPB)", the "Theory of Reasoned Action (TRA)" [18].

Understanding the cognitive-emotional and behavioural factors underlying the intention to adopt IoT for elderly NCD patients. The TPB claims that "specific cognitive-emotional and attitudinal factors underlie the intention to perform a behaviour" [19].

TPB extends the TRA by initiating perceived behavioural control [20]. TPB and its said extension "offer a valuable cognitive-emotional and environment-related framework for the explanation of behavioural intentions and behaviour" [19]. Alternatively, the Theory of Interpersonal Behaviour (TIB) is mainly used to obtain "a comprehensive understanding of what determines behaviour or what factors cause behaviour in general. It is useful in explaining and understanding complex human behaviours predominately those behaviours that are influenced by their social and physical environments" [21]. TIB thus includes all aspects of the TRA and TPB models and comprises additional elements such as facilitating conditions [22]. This study has also incorporated additional variables from TIB that have been overlooked in various research studies. According to Triandis [23], 'facilitating conditions' form "a crucial part of TIB as an individual may have the intention to perform a certain act but may be unable to do so as their environment prevents the act from being performed".

As Hair et al. [24] define it, Perceived Behavioural Control (PBC) is "an individual's perceived control over performing a particular action". TPB postulates that PBC, "attitude towards behaviour", and "subjective norms" act as antecedents to Behavioural Intention (BI) and Actual Behaviour.

The performance of a behaviour is influenced "by the presence of adequate resources and the ability to control barriers to behaviours. The more resources and fewer obstacles individuals perceive, the greater their perceived behavioural control and the stronger their intention to perform behaviours" [25]. These researchers have also suggested that attitude, PBC, and subjective norm are determinants of BI. 
However, this study has considered personal skills as one of the cognitive-emotional factors [19] that in this context refer to the problem-solving skills of an individual. The typical questions regarding personal skills are: "How do I solve my health problems using IoT?", "What can I do to solve my health problem?". This study assumes that those individuals who possess greater problem-solving skills by themselves intend to adopt IoT for healthcare.

TPB is considered most suitable for this study to understand the behaviour towards the adoption of IoT for elderly NCD patients. The capability of the TPB as a model to explore wellbeing practices was affirmed by an audit led by McEachan et al. [26].

Based on the above literature review we hypothesised that an extended TPB would have the capacity to predict both behavioural intentions and behaviour with respect to the adoption of IoT for elderly NCD patients. Figure 2 shows the conceptual framework for this study. The six hypotheses of this study are as follows:

H1(a): There is a positive association between "Intention to use IoT" and the attitude of elderly NCD patients in Malaysia.

$\mathrm{H} 2$ (b): There is a positive association between "Intention to use IoT" and the subjective norm of elderly NCD patients in Malaysia.

$\mathrm{H} 3(\mathrm{c})$ : There is a positive association between "Intention to use IoT" and perceived behavioural control of elderly NCD patients in Malaysia.

$\mathrm{H} 4(\mathrm{~d})$ : There is a positive association between "Intention to use IoT" and facilitating conditions of elderly NCD patients in Malaysia.

$\mathrm{H} 5(\mathrm{e})$ : There is a positive association between "Intention to use IoT" and problem-solving skills of elderly NCD patients in Malaysia.

H6(f): There is a positive association between actual behaviour and "Intention to use IoT" among elderly NCD patients in Malaysia.

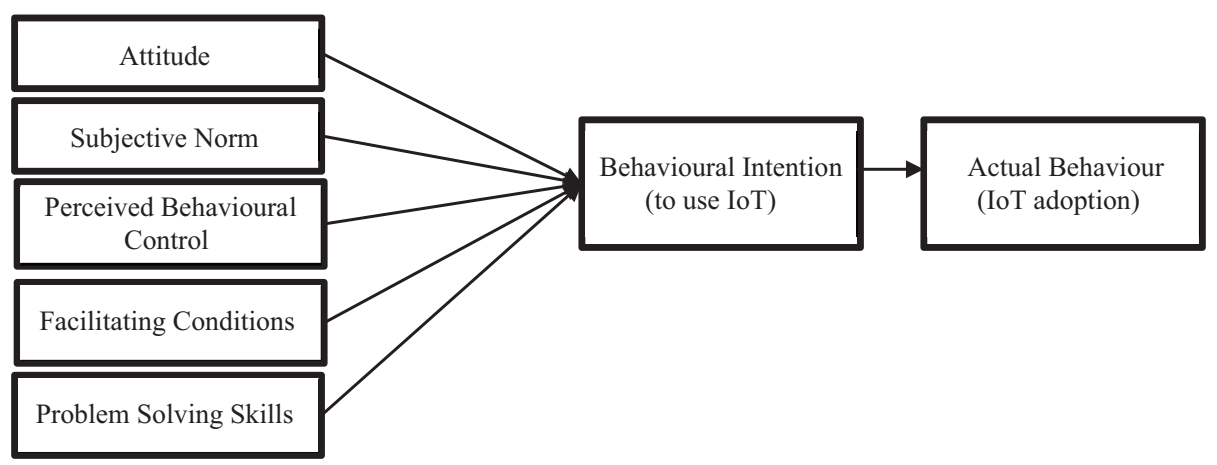

Fig. 2. Conceptual framework

\section{Proposed research method}

Malaysia is predicted to become "an aged nation" by 2030 [27]. Due to modernisation, the western lifestyle starts to invade Malaysia leading to an increase in the trend 
of lifestyle associated with NCDs. Therefore, the context of Malaysia is suitable to analyse the behaviour towards IoT adoption among elderly NCD patients. This study intends to target various hospitals and clinics located in the Selangor state of Malaysia to reach elderly NCD patients due to the higher density of the population.

The sample size in the present study will be determined based on the statistical analysis procedure suggested by previous researchers. For example, Hair et al. [28] recommends "the rule of thumb of one to five ratio (1:5)", while Kline suggests the sample size of " 10 or 15 cases per parameter" depending on the intricacy of a proposed conceptual model. However, Hair et al. [29] argue that for "confirmatory factor analysis" (CFA) and "structured equation modelling" (SEM) "the sample size of ten to one ratio (10:1)" must be followed for adequate analytical outcomes.

This study will use purposive sampling to select the respondents. This is aligned with Calder et al.'s [36] suggestion that when the priority is "theoretical generalizability" rather than "population generalizability", then "non-probability sampling" is acceptable and appropriate.

The study will be quantitative in nature. The survey will be conducted both faceto-face and online. Questionnaires will contain three sections. Section one will have questions related to the participants' socio-demographic information. Section two questions will focus on the participants' knowledge, attitude and practice regarding NCDs e.g. heart diseases, hypertension, stroke, diabetes, cervical cancer etc. The last section will contain questions related to the respondents' attitudes, perceived barriers, problem-solving skills, facilitating conditions, behavioural intentions and actual behaviour towards the use of IoT for treating NCDs. All the questionnaire items will be evaluated on a 7-point Likert scale (1-“strongly disagree"; 7-“strongly agree").

The four items of attitude towards adoption and three items of the subjective norm will be adapted from Madden et al. [30], three items of perceived behavioural control from Hair et al. [24], and the four items of adoption intention from Mathieson [31]. Self-perceived problem-solving skills will be assessed with four items adapted from Ajzen [32]. The respondents' actual behaviour will be measured based on the six items adapted from Garbharran and Thatcher [33]. Five items will be adapted from Limayem, Khalifa and Chin [34],[39],[40] to measure facilitating conditions.

Data will be analysed using CFA and SEM approaches to examine our research model [41]. The confirmatory factor analysis will be employed to test the convergent validity of the constructs used, while the SEM strategy will be adopted as it expects that singular factors are transformed individually with the other parts in the research model. The resultant model fit files will be checked in the estimation part of the model.

\section{Conclusions and future research}

Clinics or health care centres are usually the initial place where patients look for medical attention. In such a case, the shift of demography and epidemiology of these centres can impose major challenges. For an individual as well as public-level activities; chronic NCDs like heart diseases, hypertension and diabetes are challenging to handle. They also demand intensive labour from every component of the medical 
system. Identifying the disease early and primary risk factor management can help prevent NCDs among elderly patients.

Through creating awareness on the use of IoT among elderly NCD patients in Malaysia and understanding their behavioural intentions and actual behaviour can help to maximise the utilisation of the available essential services as well as equipment in the medical centres. Moreover, a further plan should be outlined to allocate services and equipment to the communal level. Studies in the future should concentrate further on the clinical aspect and utilisation of IoT wearables. The usability and cost-efficiency of these are also to be thoroughly analysed in respect to the elderly NCD population in Malaysia so that meaningful usage is ensured. Future research should focus on the empirical outcomes based on the proposed model in this study to get deeper insights on the actual behaviour towards the IoT adoption among elderly NCD patients as well.

\section{Acknowledgement}

The authors' appreciation goes to the Ministry of Higher Education Malaysia and Multimedia University for the research grant and support provided under the Fundamental Research Grant Scheme (FRGS).

\section{References}

[1] C.A.N. Malarvizhi and S.R. Manzoor, "Exploring the Significance of IoT-Enabled Health Monitoring and Assistive Systems for Elderly NCD Patients in Malaysia", available at: http://www.kmice.cms.net.my/ProcKMICe/KMICe2021/pdf/CR180.pdf

[2] B.A. Swinburn, G. Sacks, K.D. Hall, K. McPherson, D.T. Finegood, M.L. Moodie and S.L. Gortmaker, "The global obesity pandemic: shaped by global drivers and local environments". The Lancet, vol. 378(9793), pp. 804-814, 2011. https://doi.org/10.1016/S01406736(11)60813-1

[3] A. Tahir and N. Ani, "Malaysian national health and morbidity survey 2011", Kuala Lumpur: Institute of Public Health, 2012.

[4] I. Azimi, A.M. Rahmani and P. Liljeberg, "Internet of things for remote elderly monitoring: a study from user-centered perspective". J. Ambient Intelligence \& Humanized Computing, vol. 8, pp. 273-289, 2017. https://doi.org/10.1007/s12652-016-0387-y

[5] D. Goodkind and P.R. Kowal, "International population reports", US Census Bureau, 2016. https://www.census.gov/content/dam/Census/library/publications/2016/demo/p95-16-1.pdf

[6] S. Samsudin, N. Abdullah, and S.D. Applanaidu, "The prevalence of diabetes mellitus and hypertension and its effects on healthcare demand among elderly in Malaysia", Intl J. Pub Health Res., vol. 6, issue 2, pp. 741-749, 2016.

[7] C.A.N. Malarvizhi and S.R. Manzoor, "Evaluating the Use Of IoT For Healthcare Providers In Treating Elderly NCD Patients In Malaysia”, European J. Molecular \& Clinical Medicine, vol. 8, issue 2, pp. 696-705, 2021.

[8] P. Ayernor, "Diseases of ageing in Ghana", Ghana Med. J., vol. 46, issue 2 Supplementary, pp. 18-22, 2012.

[9] M.M. Abdellatif and W. Mohamed, "Telemedicine: An IoT Based Remote Healthcare System”, Intl. J. Online \& Biomed. Eng., vol. 16, issue 6, 2020. https://doi.org/10.3991/ijoe.v16i06.13651 
[10] A.S. Abdulbaqi, A.J. Obaid and S.A.H. Alazawi, "A Smart System for Health Caregiver Based on IoMT: Toward Tele-Health Caregiving”, Intl J. Online \& Biomed. Eng., vol. 17, issue 7, 2021. https://doi.org/10.3991/ijoe.v17i07.22525

[11] I.D. Sabukunze, "Designing a Smart Monitoring and Alert System for Malaria Patients Based on IoT in Burundi". Intl J. Online \& Biomed. Eng., vol. 17, issue 3, 2021. https://doi. org/10.3991/ijoe.v17i03.20369

[12] C.N. Scanaill, S. Carew, P. Barralon, N. Noury, D. Lyons and G.M. Lyons, "A review of approaches to mobility telemonitoring of the elderly in their living environment", Ann. Biomed. Eng., vol. 34, issue 4, pp. 547-563, 2006. https://doi.org/10.1007/s10439-0059068-2

[13] C.M. Boyd, and M. Fortin, "Future of multimorbidity research: how should understanding of multimorbidity inform health system design?", Pub. Health Rev., vol. 32, issue 2, pp. 451-474, 2010. https://doi.org/10.1007/BF03391611

[14] M. Tsourela and D.M. Nerantzaki, "An Internet of Things (IoT) Acceptance Model: Assessing Consumer's Behaviour toward IoT Products and Applications", Future Internet, vol. 12, issue 11, p. 191, 2020. https://doi.org/10.3390/fi12110191

[15] L. Solima, M.R. Della Peruta, and M. Del Giudice, "Object-generated content and knowledge sharing: the forthcoming impact of the internet of things", J. Know. Econ., vol. 7, issue 3, pp. 738-752, 2016. https://doi.org/10.1007/s13132-015-0243-X

[16] M. Chan, D. Estève, J.Y. Fourniols, C. Escriba, and E. Campo, "Smart wearable systems: current status and future challenges", Art. Intel. Med., vol. 56, issue 3, pp. 137-156, 2012. https://doi.org/10.1016/j.artmed.2012.09.003

[17] A.S. Ferdous, "Applying the theory of planned behaviour to explain marketing managers' perspectives on sustainable marketing". J. Intl. Cons. Mark., vol. 22, issue 4, pp. 313-325, 2020. https://doi.org/10.1080/08961530.2010.505883

[18] M. Mital, V. Chang, P. Choudhary, A. Papa, and A.K. Pani, “Adoption of Internet of Things in India: A test of competing models using a structured equation modeling approach", Tech. Forecast. \& Soc. Change, vol. 136, pp. 339-346, 2018. https://doi.org/10.1016/j.techfore. 2017.03.001

[19] F. Jalilian, M. Mirzaei-Alavijeh, M. Ahmadpanah, S. Mostafaei, M. Kargar, R. Pirouzeh, and S. Brand, "Extension of the Theory of Planned Behaviour (TPB) to predict patterns of marijuana use among young Iranian adults", Intl. J. Env. Res. \& Pub. Health, vol. 17, issue 6, 2020. https://doi.org/10.3390/ijerph17061981

[20] T. Hansen, "Consumer values, the theory of planned behaviour and online grocery shopping", Intl. J. Cons. Stud., vol. 32, issue 2, pp. 128-137, 2008. https://doi.org/10.1111/j.1470-6431. 2007.00655.x

[21] R.R. Milhausen, M. Reece, and B. Perera, "A theory-based approach to understanding sexual behavior at Mardi Gras", J. Sex Res. vol. 43, issue 2, 97-106, 2006. https://doi. org/10.1080/00224490609552304

[22] I.M.Y Woon \& L.G. Pee, "Behavioural factors affecting internet abuse in the workplaceAn empirical investigation", Proceedings of the Third Annual Workshop on HCI Research in MIS, Washington, D.C., 2004.

[23] H.C. Triandis, Interpersonal Behaviour. Monterey, C.A: Brook/Cole, 1977.

[24] J.F. Hair, C.M. Ringle and M. Sarstedt, "Partial least squares structural equation modeling: Rigorous applications, better results and higher acceptance", Long Range Planning, vol. 46, issue 1-2, pp. 1-12, 2013. https://doi.org/10.1016/j.lrp.2013.01.001

[25] I. Ajzen and T.J. Madden, "Prediction of goal-directed behaviour: Attitudes, intentions, and perceived behavioural control”, J. Exp. Soc. Psy. vol. 22, issue 5, pp. 453-474, 1986. https:// doi.org/10.1016/0022-1031(86)90045-4 
[26] R.R.C. McEachan, M. Conner, N.J. Taylor and R.J. Lawton, "Prospective prediction of health-related behaviours with the Theory of Planned Behaviour: a meta-analysis", Health Psy. Rev. vol. 5, issue 2, pp. 97-144. 2011. https://doi.org/10.1080/17437199.2010.521684

[27] B.C. Yin-Fah, T.A. Hamid, J. Masud and L. Paim, "Predictors of financial dependency in old age in Peninsular Malaysia: an ethnicity comparison", Asian Soc. Sc. vol. 6 issue 6, p. 54, 2010. https://doi.org/10.5539/ass.v6n6p54

[28] J.F. Hair, W.C. Black, B.J. Babin and R.E. Anderson, Multivariate Data Analysis. Seventh Edition. Prentice-Hall, Upper Saddle River, New Jersey, 2010.

[29] J.F. Hair Jr, G.T.M. Hult, C. Ringle and M.A. Sarstedt, Primer on Partial Least Squares Structural Equation Modeling (PLS-SEM). Sage Publications, 2016. https://doi.org/10.15358/ 9783800653614

[30] T.J. Madden, P.S. Ellen and I. Ajzen, "A comparison of the theory of planned behaviour and the theory of reasoned action”, Pers. \& Soc. Psy. Bull., vol. 18, issue 1, pp. 3-9, 1992. https:// doi.org/10.1177/0146167292181001

[31] K. Mathieson, "Predicting user intentions: comparing the technology acceptance model with the theory of planned behavior", Inf. Sys. Res., vol. 2, issue 3, pp. 173-191, 1991. https:// doi.org/10.1287/isre.2.3.173

[32] I. Ajzen, "The theory of planned behaviour: Reactions and reflections", Psy. \& Health, vol. 26, issue 9, pp. 1113-1127, 2011. https://doi.org/10.1080/08870446.2011.613995

[33] A. Garbharran and A. Thatcher, "A case for using a social cognitive model to explain intention to pirate software", J. e-Health Tech. \& Appl., vol, 7, issue 2, pp. 87-98, 2009.

[34] M. Limayem, M. Khalifa and W.W. Chin, "Factors motivating software piracy: a longitudinal study". IEEE Trans. Eng. Manag., vol. 51, pp. 414-425, 2004. https://doi.org/10.1109/ TEM.2004.835087

[35] S. Bansal, G. Chowell, L. Simonsen, A. Vespignani and C. Viboud, "Big data for infectious disease surveillance and modeling”, J. Infec. Dis., vol. 214(suppl_4), 2016. https://doi.org/ $\underline{10.1093 / \mathrm{infdis} / \mathrm{jiw} 400}$

[36] B.J. Calder, L.W. Phillips and A.M. Tybout, "The concept of external validity", J. Cons. Res., vol. 9, issue 3, pp. 240-244, 1982. https://doi.org/10.1086/208920

[37] L.A. Durán-Vega, P.C. Santana-Mancilla, R. Buenrostro-Mariscal, J. Contreras-Castillo, L.E. Anido-Rifón, M.A. García-Ruiz and F. Estrada-González, "An IOT system for remote health monitoring in elderly adults through a wearable device and mobile application", Geriatrics, vol. 4, issue 2, p. 34, 2019. https://doi.org/10.3390/geriatrics4020034

[38] R. Lun, C. Gordon and W. Zhao, "The design and implementation of a Kinect-based framework for selective human activity tracking". In 2016 IEEE International Conference on Systems, Man, and Cybernetics (SMC) (pp. 002890-002895). IEEE, 2016, October. https:// doi.org/10.1109/SMC.2016.7844678

[39] P.C. Santana-Mancilla and L.E. Anido-Rifón, "The technology acceptance of a TV platform for the elderly living alone or in public nursing homes", Intl J. Env. Res. \& Pub. Health, vol. 14, issue 6, p. 617, 2017. https://doi.org/10.3390/ijerph14060617

[40] M.I. Qureshi, N. Khan, H. Raza, A. Imran and F. Ismail, Digital Technologies in Education 4.0. Does it Enhance the Effectiveness of Learning? A Systematic Literature Review. International Journal of Interactive Mobile Technologies. 2021 Apr 1;15(4). https://doi. org/10.3991/ijim.v15i04.20291

[41] I. Mustapha, N.T. Van, M. Shahverdi, M.I. Qureshi and N. Khan, Effectiveness of Digital Technology in Education During COVID-19 Pandemic. A Bibliometric Analysis. International Journal of Interactive Mobile Technologies. 2021 Aug 1;15(8). https://doi. org/10.3991/ijim.v15i08.20415 


\section{Authors}

Chinnasamy Nambi Agamudai Malarvizhi, Multimedia University, 63100 Cyberjaya, Selangor, Malaysia.

Shamima Raihan Manzoor, Multimedia University, 63100 Cyberjaya, Selangor, Malaysia. E-mail: shamimaraihanmanzoor@gmail.com

Sreenivasan Jayashree, Multimedia University, 63100 Cyberjaya, Selangor, Malaysia.

Article submitted 2021-07-04. Resubmitted 2021-08-26. Final acceptance 2021-08-27. Final version published as submitted by the authors. 